\title{
Relation of Work-life Balance to Counterproductive Work Behavior and Turnover Intention among Malaysian Employees
}

\author{
Ting-Ying Tan
}

Department of Psychology and Counselling, Universiti Tunku Abdul Rahman, Perak, Malaysia

*Corresponding author:

Ting-Ying Tan

Department of Psychology and Counselling

Universiti Tunku Abdul Rahman

Perak, Malaysia

Email address: tantingy@utar.edu.my 


\title{
Relation of Work-life Balance to Counterproductive Work Behavior and Turnover Intention among Malaysian Employees
}

\begin{abstract}
Work-life balance is receiving increasing attention from researchers and organizations, especially policy makers looking to improve employees' productivity. With the changing work culture and flexible working arrangements, employees are more focused on both work and nonwork matters instead of only having a focus on work. As both parents are often working, relationships with children may be affected. Thus, worklife balance not only has an impact on the individuals, but also on work quality, relationships with colleagues, and family life. This study aims to explore the relationship of work-life balance with counterproductive work behavior and turnover intention. Another purpose of the study is to examine the gender difference in work-life balance. The results showed there was a significant relationship between work-life balance and counterproductive work behavior, a significant relationship between work-life balance and turnover intention, but no significant difference in work-life balance between female and male respondents. The research finding is able to contribute to the literature on work-life balance, counterproductive work behavior, and turnover intention. Work-life balance is suggested to be included in organization policy or employee welfare programs; once their wellbeing is well taken care of, employees will be able to contribute more to the organizational success.
\end{abstract}

Keywords: work-life balance, counterproductive work behaviour, turnover intention, working employees, Malaysia

\section{Introduction}

\section{Background}

Employees constitute, as a category, one of the most precious company assets. If the employer takes care of their employees, the employees will put more effort into working and strive for organizational success. Among many factors that may influence employees, worklife balance appears to be one of the requirements employees look for. Work-life balance (WLB) is defined as the extent to which a person is engaged in and equally satisfied with their roles, both the work role and family role (Greenhaus, Collins, \& Shaw, 2003). WLB is receiving continuous interest from organizations and individuals because individuals will enjoy better health and wellbeing if they have a balance between work and nonwork (Zheng, Molineux, Mirshekary, \& Scarparo, 2015). However, WLB has not received enough focus and remains one of the least studied concepts in work-life research (Haar, Russo, Sune, \& Ollier-Malaterre, 2014; Greenhaus, \& Allen, 2011).

What makes research difficult is that WLB varies according to individuals. There are many tips about achieving WLB, but it can be hardly practiced often due to lack of attention and effort from the organization. Women are perceived to have a poorer WLB than men due to societal gender stereotypes (Lyness, \& Judiesch, 2013). This finding was consistent with Allen (Allen \& Finkelstein, 2014) that women reported not having a WLB compared to men. In contrast, another study (Sav, Harris, \& Sebar, 2013) found that men had a poorer WLB, as 
they are the financial providers for their families, which leads them to work longer hours to meet the family obligations. Also, men and women differ in working arrangements, especially in terms of flexible working arrangements, where flexibility leads to a decrease in WLB for men (Chung, 2018).

Turnover has been a troublesome issue for most organizations. This is because after employees leave, the company needs to hire and train new workers. It is time-consuming and costly if employees keep changing. Furthermore, the turnover rate will also influence the company's reputation and the mental state of remaining workers. Turnover intention refers to employees' willingness or attempts to leave the current workplace voluntarily (Takase, 2010). As reported by Fiona (2010), about 40 percent of Malaysian employees quoted WLB as the main reason for them to stay in the current workplace. Thus, it shows the importance of promoting WLB for employees. Furthermore, WLB not only affects individuals, but it also brings an impact to family members, for instance, if children are deprived of quality time with their parents, this can lead them into adulthood without proper guidance, which in turn potentially creates another social issue (Fiona, 2017).

On the other hand, some companies only have WLB policies for employees with families, and have neglected employees who are single. The perceived unfairness may lead to counterproductive work behavior (CWB) (Wilkinson, Tomlinson, \& Gardiner, 2018). In addition, solo-living employees also complain that organizational policies only priorities the needs of working parents. In contrast, Paluch and Nishii (2017) reported that organizational involvement in work-life benefits may produce CWB due to worry or guilt. The gap in expectations may be a sign of CWB and turnover. As employees' needs are not fulfilled, they may seek other job opportunities that can meet their needs.

\section{Trends of Work-life Balance in Malaysia}

Changes in the workforce and work style have been taking place (Ramos, Francis, \& Philipp, 2015). The advancement in technology, globalization, and the increasing proportion of female workers in different industries showed the evolution of the workforce. Employees who have WLB also enjoy a better quality of life. Employees who had always worked longer hours also now demand a WLB. Nevertheless, most companies are not aware of their needs. Most of the companies only offer the WLB program to female workers. Malaysian employers ignore the importance of WLB for both male and female employees even though all employees, regardless of gender, look for WLB as a top priority ("Malaysian employers", 2017) One of the reasons WLB is being ignored is because employers hold a perception that employees work for wages only (Fiona, 2017). Another reason is that employers tend to overlook the role of the male in family life. Men are perceived culturally as the breadwinner in the family, and they often carry less of a family role compared to working mothers. Despite the fact that working fathers also hold certain childcare responsibilities, they still need WLB for better job performance and healthy wellbeing (Hughes \& Bozionelos, 2007). Employees may have been showing a continuous need for WLB for a few years, but their voice is not being heard. In 2017, the Advisory, Development, Learning and Achievement Group (ADLA) organized the first Work-Life Balance School for entrepreneurs in Malaysia, 
supported by the Ministry of Malaysia. This action shows the effort of both local employers and the Malaysian government in improving employees' WLB through the event. The founder of ADLA emphasized that employers need to ensure that employees are provided with enough of a support system within the office environment and life since employees are drained by overwork (Chung, 2018). Workplace factors such as supervisor support, coworker support, and flexible working arrangements were reported as contributing to WLB in the Malaysian context (Wong, Bandar, \& Saili, 2017).

Table I summarizes the research trend of WLB in Malaysia. Previous research focused on quality of work life and the balance of employees purely at work. However, the influence of family role and family conflicts experienced by the employee directly impacted on their job performance and job satisfaction. Then, there was a research focus switch from quality of work life to WLB as the researchers noticed the importance of work and family balance. However, WLB is not being fully utilized by employers despite the fact that research had proven its benefits. There is still a major research gap about WLB in Malaysia due to the scarce research background. Also, previous studies only examined how WLB affected work without looking at other perspectives such as the consequences of low WLB. This study intends to examine the relationship of WLB, turnover intention and CWB.

Table I. Work-life Balance Research in Malaysia

\begin{tabular}{|c|c|}
\hline Focus & Sub-theme \\
\hline $\begin{array}{l}\text { This paper identified the relationship between qualities of work life } \\
\text { (QWL) and career balance (family and work). Career balance was } \\
\text { the least satisfied with the level of QWL. This paper suggested } \\
\text { future studies to understand the need for work-life balance (WLB) } \\
\text { (Rose, Beh, Uli, \& Idris, 2006). }\end{array}$ & $\begin{array}{l}\text { Quality of work life, working conditions, } \\
\text { career balance }\end{array}$ \\
\hline $\begin{array}{l}\text { This paper examined the relationship between perceived WLB } \\
\text { satisfaction of academics in Malaysian public higher education } \\
\text { institutions, and their intentions to leave the organization. A total of } \\
1078 \text { participants were recruited. The results indicated a negative } \\
\text { correlation between perceived WLB and intention to leave (Noor, } \\
\text { 2011). }\end{array}$ & Perceived WLB, turnover intention \\
\hline $\begin{array}{l}\text { This paper examined the relationship between job security and } \\
\text { QWL in a multinational firm. Significant correlation was found. } \\
\text { This paper emphasized the importance of work-life study in the } \\
\text { future (Noor \& Abdullah, 2012). }\end{array}$ & Work life study, QWL, job security \\
\hline $\begin{array}{l}\text { This paper compared eastern and western perspectives on WLB. } \\
\text { The Malaysian sample showed strong negative correlation in } \\
\text { family-interfere-work and the working environment provided in the } \\
\text { family-friendly companies. Malaysian participants were required to } \\
\text { work long hours and had limited parental leave (Chandra, 2012). }\end{array}$ & WLB, working hours, family-interfere-work \\
\hline $\begin{array}{l}\text { This paper investigated the effect of a flexible working arrangement } \\
\text { (FWA) on WLB; the results showed FWA did have an effect on } \\
\text { WLB in a positive way. The study recommended attitudinal shifts } \\
\text { on the part of employers and Malaysian society, as employers play } \\
\text { a bigger role in ensuring WLB of employees (Subramaniam, } \\
\text { Overton, \& Maniam, 2015). }\end{array}$ & $\begin{array}{c}\text { Flexible working arrangement, WLB, role of } \\
\text { employer }\end{array}$ \\
\hline
\end{tabular}




\section{Components Approach on Work-life Balance}

The components approach is one of the contemporary views on WLB (Wong, Bandar, \& Saili, 2017). It emphasizes the balance between work and family. Instead, of focusing on measures on work or family, it defined WLB using an overall evaluation of how well an individual is meeting role-related responsibilities (Rose, Beh, Uli, \& Idris, 2006). Hence, WLB is defined as the effort of equally engaging and satisfying the individual's work and family roles (Greenhaus et al., 2003). In other words, employees who have a good WLB do not necessarily spend an equal amount of time on both work and family, but the idea implies having a balance between the roles of an employee and a family member. Whether the individual is more in favor of work or nonwork roles, as long as the individual is engaged and satisfied, then he or she will be said to have WLB. Moreover, WLB or imbalance are not necessarily detrimental to the individual; the imbalance, according to (Greenhaus et al., 2003), is beneficial to the individual's psychological well-being and quality of life, the imbalance being in favor of either work or family.

\section{Purpose of Study}

As most companies in Malaysia do not focus on WLB, future intervention should emphasize policy or programs that concentrate on fostering WLB among employees, without only prioritizing employees with children. This is because it will create unfairness among employees who are single and have less commitment to family. As turnover is directly linked to organizational performance, integrating WLB elements into retention programs can be helpful to keep the talents within the company. Furthermore, the WLB program can be used for both genders, regardless of their work roles and family roles. One of the ways to tackle the issue is by incorporating flexible working hours and adjusting total working hours for employees (Chung, 2018).

This study aims to examine the relationship between CWB and WLB and the relationship between turnover intention and WLB. This study also aims to explore the gender difference in WLB.

Based on the above discussion, three hypotheses are presented to test in the study:

- H1: There is a significant relationship between CWB and WLB.

- H2: There is a significant relationship between turnover intention and WLB.

- H3: There is a significant difference in WLB among male and female employees.

\section{Methods}

This study used a quantitative research design (cross-sectional design) for data collection and data analysis. Convenience sampling was used to recruit participants. A total of 399 participants were recruited. They are working employees with an age range from 18 to 57 . Before questionnaires were distributed, ethical approval was gained from Universiti Tunku Abdul Rahman Scientific Ethical Review Committee. Informed consent was attached as the first page of the questionnaire, and a signature from participants was required before they start answering the questionnaire. The questionnaire consisted of four sections, which 
included three existing questionnaires and demographic data of participants. The Industrial Society's Work-Life Balance Checklist developed by Daniels and McCarraher (2000) was used to measure participants' WLB with a total of 10 items. The participants were required to choose from "Agree", "Sometimes", and "Disagree". Example of items included the following: "I have to take work home most evenings," "my relationship with my partner is suffering because of the pressure or long hours of my work," and "finding time for hobbies, leisure activities, or to maintain friendships and extended family relationship is difficult." The CWB Checklist developed by Spector et al. (2006) was used to assess CWB such as aggression, sabotage, and theft. The checklist consisted of 32 items; the participants were asked to rate based on a 5-point Likert scale where 1 is Never and 5 is Every day. Examples of items included: "purposely damaged a piece of equipment or property," "been nasty or rude to a client or customer," and "said something obscene to someone at work to make them feel bad." The Turnover intention scale developed by Camman, Fichman, Jenkins, and Klesh (1979) consists of three items. Participants were asked to rate based on a 5-point Likert scale where 1 is Strongly Disagree and 5 is Strongly Agree. An example of the items included "as soon as possible, I will leave the organization." The data analysis used was Pearson Correlation to ascertain the relationship between WLB and CWB, and the relationship between WLB and turnover intention. A T-test was used to identify the differences in WLB among males and females.

\section{Results}

\section{Reliability of Questionnaire}

Before data analysis was conducted to test hypotheses, the reliability for the three questionnaires was analyzed as shown in Table II.

Table II. Reliability Statistics

\begin{tabular}{cccc}
\hline Section & $\begin{array}{c}\text { Cronbach's } \\
\text { Alpha }\end{array}$ & $\begin{array}{c}\text { Cronbach's } \\
\text { Alpha based on } \\
\text { standardized } \\
\text { items }\end{array}$ & $\begin{array}{c}\text { N of } \\
\text { items }\end{array}$ \\
\hline $\begin{array}{c}\text { The Industrial } \\
\text { Society's Work-Life } \\
\text { Balance Checklist }\end{array}$ & 0.85 & 0.84 & 10 \\
\hline $\begin{array}{c}\text { Counterproductive } \\
\text { Work Behaviour } \\
\text { (CWB) Checklist }\end{array}$ & 0.96 & 0.96 & 32 \\
\hline $\begin{array}{c}\text { Turnover Intention } \\
\text { Scale }\end{array}$ & 0.88 & 0.88 & 3 \\
\hline
\end{tabular}

\section{Relationship between Work-life Balance, Counterproductive Work Behaviour, and} Turnover Intention

There was a negative correlation between WLB and CWB, $r=-0.26, n=399, p<0.001$, with high level of WLB associated with lower level of CWB. WLB helps to explain nearly 7 percent of the variance in respondents' scores on the CWB. 
On the other hand, there was a negative correlation between WLB and turnover intention, $r=$ $-0.30, n=399, p<0.001$, with an increasing level of WLB correlating with a decreasing level of turnover intention. WLB helps to explain 9 percent of the variance in respondents' scores on turnover intention.

Table III showed the correlation coefficient of the three variables.

Table III. Correlations Between Work-life Balance, Counterproductive Work Behavior, and Turnover Intention

\begin{tabular}{cccc}
\hline Scale & $\begin{array}{c}\text { Work-life } \\
\text { balance }\end{array}$ & $\begin{array}{c}\text { Counterproductive } \\
\text { work behavior }\end{array}$ & $\begin{array}{c}\text { Turnover } \\
\text { intention }\end{array}$ \\
\hline Work-life balance & 1.00 & $-0.26^{* *}$ & $-0.30^{* *}$ \\
\hline $\begin{array}{c}\text { Counterproductive work } \\
\text { behavior }\end{array}$ & $-0.26^{* *}$ & 1.00 & $0.22^{* *}$ \\
\hline Turnover intention & $-0.30^{* *}$ & $0.22^{* *}$ & 1.00 \\
\hline
\end{tabular}

** Correlation is significant at the 0.01 level (2-tailed).

This study also further explores whether CWB and Turnover Intention (TI) can predict WLB (see Table IV). Linear regression analysis was used to test the hypotheses. The model was statistically significant, $F(2,394)=28.24, p<0.001$ and accounted for $12.1 \%$ of the variance. It was found that TI is the best predictor $(\beta=-0.248, p<0.001)$ compared to CWB $(\beta=-0.206, p<.001)$. $\mathrm{H} 1$ and $\mathrm{H} 2$ are supported.

Table IV. Summary of Multiple Regression Analysis for Variables Predicting Work-life Balance ( $=$ 401)

\begin{tabular}{|c|c|c|}
\hline & Turnover intention & $\begin{array}{c}\text { Counterproductive } \\
\text { work behaviors }\end{array}$ \\
\hline & $\begin{array}{l}\text { Standardized } \\
\text { coefficients }\end{array}$ & $\begin{array}{c}\text { Standardized } \\
\text { coefficients }\end{array}$ \\
\hline Variable & $\beta$ & $\beta$ \\
\hline $\begin{array}{l}\text { Work-life } \\
\text { Balance }\end{array}$ & -0.248 & -0.206 \\
\hline$R^{2}$ & \multicolumn{2}{|c|}{0.125} \\
\hline$F$ & \multicolumn{2}{|c|}{28.24} \\
\hline
\end{tabular}

\section{Gender Difference in Work-life Balance}

There was no significant difference in scores for the genders in WLB, males $(M=19.22, S D$ $=4.85)$ and females $(M=20.45, S D=4.84) ; t(401)=-2.55, p=0.98$. Males and females do not differ in the level of WLB, even though they held different positions at work and multiple roles in family. H3 is not supported. 
Table V. T-Test Results Comparing Males and Females on Work-life Balance

\begin{tabular}{lccclll}
\hline \multicolumn{3}{c}{ Female } & \multicolumn{2}{c}{ Male } \\
\hline & $\boldsymbol{M}$ & $\boldsymbol{S D}$ & $\boldsymbol{M}$ & & $\boldsymbol{M}$ & \\
\hline Work-life balance & 20.45 & 4.84 & 19.22 & $\begin{array}{c}\text { Work-life } \\
\text { balance }\end{array}$ & 20.45 & \\
\hline
\end{tabular}

\section{Discussion and Limitations}

The research finding showed there is a significant negative relationship between CWB and WLB; CWB was able to predict WLB such that with a decrease of CWB there is an increase in WLB. This may be due to CWB being used as a tool to express negative emotions and unfairness when employees cannot achieve WLB (Beauregard, 2014). Meanwhile, although employees with WLB will not display destructive behavior on company property, the quality of the relationship between supervisors and colleagues suffer if the employee's attitude is more favorable toward family (Suyasa, 2017). As discussed in the components approach, WLB is not spending an equal amount of time on both work and nonwork matters; thus, the favoritism may lead to another issue. Furthermore, nothing is perfect; it hardly leads to quality relationships in either work or family roles. In order to maintain WLB, Malaysian employers can take note on employees who displayed CWB, and investigate the root cause of it instead of giving punishment. This is because Malaysian employees tend to be passive in the working place and maintain a silence culture even if they have grievances (Brunoehler, 2016).

WLB correlated with turnover intention. This finding was consistent with Jnaneswar (2016) who revealed a significant relationship between WLB and turnover intention. Accordingly, the intention to leave is one of the major predictors, and an immediate sign of employees' turnover. Organizations need to help their employees in balancing the work and nonwork roles, so the turnover intention will diminish. Malaysian employers can consider taking a quick survey among their employees to tackle this issue. As turnover intention is one of the predictors for low WLB, employers may incorporate face-to-face communication with the employees since silence remains as workplace culture obstacle to communication in Malaysia.

Despite the inconsistencies of past findings regarding WLB in terms of gender, this study revealed that there was no significant difference in the WLB level between male and female employees. This finding is consistent with Mas-Machuca (Subramaniam et al., 2015) indicating that gender does not differ in terms of WLB. The reason is that the managers are aware of the relevance of employee WLB, and the organizational culture, which recognizes the importance of WLB, also remains as one of the contributors to the said result.

Besides organizations, individuals also need to learn to balance work and nonwork roles to reduce the discrepancies between the two. If the organizations or immediate supervisor are 
not supportive, they can make deliberate attempts to relax by taking personal time off from work and participate actively in family activities (Ramos et al., 2015).

With the research findings, it is suggested that both organizations and employees themselves need to take responsibility in instilling WLB. As employees have different priorities, they may have different views toward WLB. Supervisors should show more support toward their subordinates and be aware of their needs. Organization policymakers also need to be aware of the individual differences when amending or creating WLB programs.

One of the limitations of this study is the context of research. As the convenient sampling method is being employed, we can only reach the participants willing to join the research. Future research can cooperate with the organization to collect data, so the results will be more representative. Next, even though we ensure the confidentiality of data from participants, some participants still will answer the questionnaire based on a socially acceptable response. Other than that, cross-sectional research design cannot identify the cause and effect of WLB. In-depth research is needed, such as a longitudinal and experimental design.

\section{Conclusion}

From the research results, the participants with good WLB will not display CWB and their turnover intention is low. This showed the importance of fostering WLB in organizations. The research provides some insights to organizations in terms of the direction needed in creating or improving current programs regarding WLB or retention programs. The growing workforce concerns regarding WLB demonstrate the need for providing WLB initiatives. By enhancing WLB among employees, organizations' support from their employees will increase, which in turn will raise productivity and performance.

\section{Acknowledgment}

The data collection of this research is completed by Universiti Tunku Abdul Rahman students pursuing Bachelor of Social Science (Hons) Psychology, who took the subject UAPG1013 Statistical Techniques for Behavioural Science 1, January 2018.

\section{References}

Allen, T. D., \& Finkelstein, L. M. (2014). Work-family conflict among members of full-time dual-earner couples: An examination of family life stage, gender, and age. Journal of Occupational Health Psychology, 19(3), 376-384.

Beauregard, T. A. (2014). Fairness perceptions of work-life balance initiatives: Effects on counterproductive work behavior. British Journal of Management, 25(4), 772-789.

Brunoehler, P. (2016). Understanding the culture of silence in Malaysian offices. Retrieved November 1, 2018, from http://www.expatgo.com/my/2016/12/30/understanding-culture-silence-malaysian-offices/

Chandra, V. (2012). Work-life balance: Eastern and Western perspectives. The International Journal of Human Resource Management, 23(5), 1040-1056. 
Chung, H. (2019). 'Women's work penalty' in access to flexible working arrangements across Europe. European Journal of Industrial Relations, 25(1), 1-18.

Fiona, J. (2017, October 31). Employees need to strive for work-life balance-Women's ministry. New Straits Times. Retrieved from https://www.nst.com.my/news/nation/2017/10/297543/employees-need-strivework-life-balance-womens-ministry

Greenhaus, J. H., Collins, K. M., \& Shaw, J. D. (2003). The relation between work-family balance and quality of life. Journal of Vocational Behavior, 63(3), 510-531.

Greenhaus, J. H., \& Allen, T. D. (2011). Work-family balance: A review and extension of the literature. In J. C. Quick and L. E. Tetrick (Eds.), Handbook of occupational health psychology (pp. 165-183). Washington, DC: American Psychological Association.

Grzywacz, J. G., \& Carlson, D. S. (2007). Conceptualizing work-family balance: Implications for practice and research. Advances in Developing Human Resources, 9(4), 455-471.

Haar, J. M., Russo, M., Sune, A. \& Ollier-Malaterre, A. (2014). Outcomes of work-life balance on job satisfaction, life satisfaction and mental health: A study across seven cultures. Journal of Vocational Behavior, 85(3), 361-373.

Hughes, J., \& Bozionelos, N. (2007). Work-life balance as source of job dissatisfaction and withdrawal attitudes: An exploratory study on the views of male workers. Personnel Review, 36(1), 145-154.

Jnaneswar, K. (2016). Relationship between work-life balance, turnover intention, and organizational support for work-life balance: A study in the IT industry in Kerala. Prabandhan: Indian Journal of Management, 9(5), 33-44.

Malaysian employers turn a blind eye to work-life balance-study. (2017, May 25). The Edge Financial Daily. Retrieved from https://www.theedgemarkets.com/article/malaysian-employers-turn-blind-eye-worklifebalance-\%E2\%80\%94-study

Noor, K. M. (2011). Work-life balance and intention to leave among academics in Malaysian public higher education institutions. International Journal of Business and Social Science, 2(11), 240-248.

Noor, S. M., \& Abdullah, M. A. (2012). Quality work life among factory workers in Malaysia. Procedia Social and Behavioral Sciences, 35, 739-745.

Rantanen, J., Kinnunen, U., Mauno, S., \& Tillemann, K. (2011). Introducing theoretical approaches to work-life balance and testing a new typology among professionals. In S. Kaiser, M. E. D. R. Ringlstetter, \& M. Pian e Cunha (Eds.), Creating Balance? International perspectives on the work-life integration of professionals (pp. 27-46). Berlin, Germany: Springer.

Sav, A., Harris, N., \& Sebar, B. (2013). Work-life conflict and facilitation among Australian Muslim men. Equality, Diversity and Inclusion: An International Journal, 32(7), 671-687.

Subramaniam, G., Overton, J., \& Maniam, B. (2015). Flexible working arrangements, work life balance and women in Malaysia. International Journal of Social Science and Humanity, 5(1), 34-38.

Suyasa, P. T. Y. S. (2017). The role of quality of work-life as predictor of counterproductive work behavior. Anima Indonesian Psychological Journal, 32(3), 169-183.

Takase, M. (2010). A concept analysis of turnover intention: Implications for nursing management. Collegian, $17(1), 3-12$.

Wilkinson, K., Tomlinson, J., \& Gardiner, J. (2018). The perceived fairness of work-life balance policies: A UK case study of solo-living managers and professionals without children. Human Resource Management Journal, 28(2), 325-339.

Wong, P.-Y., Bandar, N. F. A., \& Saili, J. (2017). Workplace factors and work-life balance among employees in selected services sector. International Journal of Business and Society, 18(S4), 677-684.

Zheng, C., Molineux, J., Mirshekary, S., \& Scarparo, S. (2015). Developing individual and organisational worklife balance strategies to improve employee health and wellbeing. Employee Relations, 37(3), 354-379. 